\title{
Failure of cigarette smoking to explain international differences in mortality from chronic obstructive pulmonary disease
}

\author{
C A Brown, I K Crombie, Hugh Tunstall-Pedoe
}

\begin{abstract}
Study objective - The study aimed to explain international differences in rates and trends of chronic obstructive pulmonary disease (COPD) using two measurements of cigarette smoking, the major risk factor for this disease.

Design - Mortality data for COPD were obtained from the World Health Organisation for 31 countries from 1979 to 1988 . Smoking data were obtained for most countries. COPD rates were compared to the percentage of current smokers and past levels of cigarette consumption. COPD trends were compared to past consumption trends.

Main results - In men, Romania had the highest COPD mortality and Greece the lowest throughout the period. English speaking countries occupy most of the other top positions, and southern European countries and Japan the low positions. Women show a similar ranking to men $(r=0.75 ; p<0.01$ (1988)). Mortality rates in men are, in general, two to four times those in women. Most countries show either a decrease or no change in COPD mortality over the period. In women the opposite is true - no clear relationships are seen when comparing rates and trends of COPD with measures of smoking.

Conclusion - This failure to explain international COPD differences suggests that national data on COPD may be unreliable or national cigarette smoking data are inadequate, or both.
\end{abstract}

\section{( $\mathcal{F}$ Epidemiol Community Health 1994;48:134-139)}

Chronic obstructive pulmonary disease (COPD) is a major cause of death in developed countries worldwide. ${ }^{12}$ Mortality from chronic bronchitis has been falling for the past 20 years in a number of countries, including the $\mathrm{UK},{ }^{3}$ the USA, and Canada. ${ }^{4}$ More deaths are being coded as "chronic airways obstruction", however, a term first recognised at a Ciba symposium in $1959 .{ }^{5}$ Since the introduction of the ninth revision of the International Classification of Diseases (ICD), which included a code (496) for this disease, there has been an increase in mortality from it in the $\mathrm{UK}^{6}$ and the USA and Canada, ${ }^{4}$ with deaths being coded more frequently as chronic airways disease than chronic bronchitis. ${ }^{47}$ There is, however, wide variation in coding practices for respira- tory disease between bronchitis and airways disease throughout the world, ${ }^{89}$ with many eastern European and Scandinavian countries favouring bronchitis and English speaking countries airways disease. For this reason, Thom $^{2}$ has recommended combining these diseases as "chronic obstructive pulmonary disease" (ICD codes 490 to 496) and also including asthma and emphysema to give a clearer picture of what is happening to rates of respiratory disease worldwide.

Rates and trends for COPD in men and women aged 35-74 years from 31 countries are examined for the period 1979-88. Data on all COPD rates worldwide are available from the World Health Organisation (WHO) in the introduction of the ICD ninth revision (1979). We extend the time period of a previous study, ${ }^{2}$ which compared COPD mortality internationally between 1979 and 1985, and endeavour to explain international variation using measurements of cigarette smoking, which is recognised as the major risk factor for COPD. ${ }^{1011}$ This had not been attempted previously. ${ }^{2}$

\section{Methods}

Mortality statistics for all COPD (ICD revision 9, codes 490 to 496) were obtained directly from WHO for the period 1979 to 1988. Thirty one countries were selected for analyses, based on a previous study which chose these countries because they satisfied death certification and data availability criteria. ${ }^{2}$ Two countries, Denmark and Switzerland, continue to use the ICD eighth revision (codes 490 to 493) and the three other Scandinavian countries only recently adopted the ninth revision coding. Thirteen of the countries do not have mortality statistics available for 1988. Rates per 100000 population are for the age group 35 to 74 years and were age standardised to the WHO European standard population. ${ }^{12}$

Data on the percentage of current smokers for as many of the 31 countries as possible were obtained from ASH (Action on Smoking and Health) and the World Health Statistics Quarterly. ${ }^{13}$ Data for England and Wales, Northern Ireland, and Scotland are combined under the United Kingdom (UK). Data for the percentages of current smokers (which are for the most recent year available) were not available for Bulgaria, East Germany (GDR), Iceland, and Yugoslavia. The percentages of current smokers were compared with COPD mortality 
rates using Spearman's rank correlation coefficient.

Past data on the percentages of current smokers were obtained for Australia, ${ }^{14}$ Netherlands, ${ }^{15}$ the UK, ${ }^{16}$ and the USA [ASH, personal communication]. Data on the percentages of ever smokers were obtained for 10 countries - Belgium, Denmark, France, Italy, Netherlands, the UK, West Germany, ${ }^{17}$ Australia, ${ }^{14}$ Canada, and the USA (ASH), and these percentages were compared with COPD mortality rates using Spearman's rank correlation coefficient.

Data on cigarette consumption per adult from 1945-73 were obtained for 22 countries (UK countries combined) from Lee. ${ }^{18}$ Data were not available for the eastern European countries and Israel for this period. Data from 1970 and 1975-85 were obtained for all the European countries from $\mathrm{ASH}$ and for the USA and Japan from two other sources, ${ }^{1920}$ but no data were available for Australia, Canada, New Zealand, and Israel except for $1985^{13}$ (data also extracted for $1970^{13}$ where not known from the other sources). Levels of consumption at various times were compared with COPD mortality over the period 1979-88 using Spearman's rank correlation coefficient. Trends in consumption were compared with trends in COPD mortality by examining absolute differences in consumption levels over certain time periods with the change in COPD levels from 1979-88.

\section{Country}

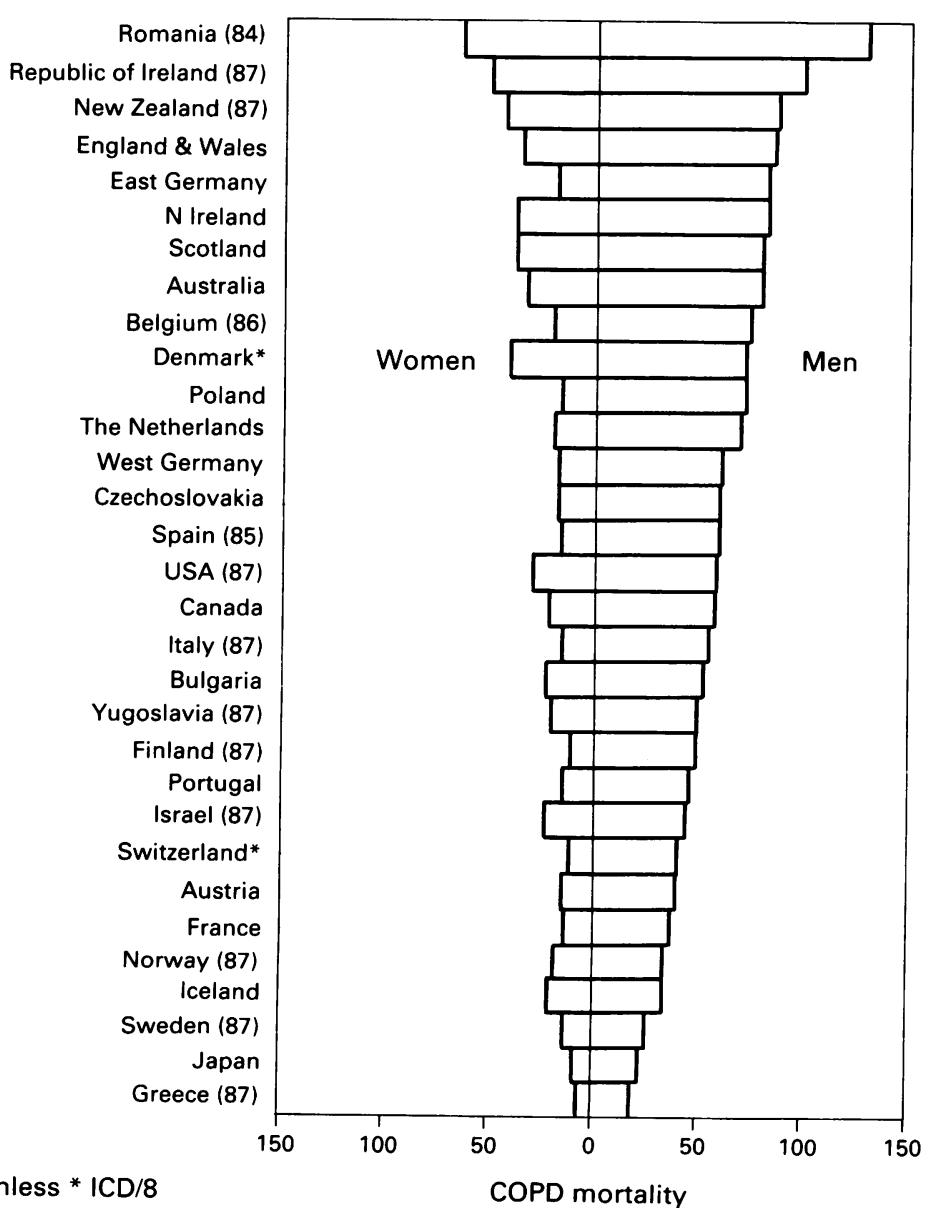

$\mathrm{ICD} / 9$ unless * $\mathrm{ICD} / 8$

COPD mortality

Figure 1 Death rates per 100000 for chronic obstructive pulmonary disease by sex in people aged 35-74 years in 1988 (unless stated).

\section{Results}

WORLD RANKINGS IN COPD MORTALITY

The age standardised COPD rates for men and women aged 35 to 74 years for the 31 countries in 1988 (or the most recent available year) are shown in Figure 1. The ranking is by male COPD mortality. There is a large spread of rates in men - Romania is highest (128.3/ 100000 (1984)) and Greece lowest (18.8/ 100000 (1987)). Australia, the Republic of Ireland, New Zealand, and the countries comprising the UK, occupy six of the top eight positions. The remaining eastern European countries along with Canada and the USA occupy middle ranking positions. Countries in western Europe are spread throughout the range with Belgium, the Netherlands, and West Germany (FRG) in the top half and Austria, France, and Switzerland near the bottom of the rankings. Southern European countries, Iceland, and Scandinavia, with the exception of Denmark, have low mortality and Japan has the second lowest rate.

The rankings in women are similar to those in men, with a highly significant correlation $(0.75, \quad \mathrm{p}<0.01)$ between the most recent COPD rates. As with men, Romania has the highest rate $(64 \cdot 8 / 100000)$ and Greece the lowest $(7 \cdot 0 / 100000)$. Israel and Iceland, which had low male rankings, are considerably higher in the female rankings. The East German ranking of 17 th in women compares with a ranking of 5 th in men. In general, men have a rate of COPD two to four times that of women (from 1.61 for Iceland to 4.45 for Norway). The male:female ratios are based on the most recent year available.

\section{TRENDS IN COPD MORTALITY}

Differences were found between countries in the mortality trend in men from 1979-88. These trends were grouped into three categories: (i) a group showing a decrease in COPD mortality $\geq 2 / 100000$; (ii) a group with an increase in COPD mortality $\geq 2 / 100000$; (iii) a group with little change in COPD mortality $<2 / 100000$. Each category is illustrated in Figure 2. The rates are expressed as three year averages (1979-81, 1980-82, etc) to smooth year to year fluctuations. The trend shown by 17 of the countries including Scotland, England and Wales, and Bulgaria, was of a decrease in rates. Czechoslovakia showed the most appreciable decline, with the rate being almost halved from $109 \cdot 2 / 100000$ in 1979 to $59.9 / 100000$ in 1988. The USA and Denmark show an increase in COPD rates which is also the case for seven other countries. Japan is one of five countries whose rate remained constant over the period.

In contrast to men, 16 of the countries examined showed an upward trend in COPD rates in women from 1979-88 (Fig 3). Scotland, England and Wales, and the USA show a small upward trend in Figure 3, but Denmark shows the most appreciable increase in rates (23.6/100 000 in 1979 to $41 \cdot 8 / 100000$ in 1988). Bulgaria and Czechoslovakia show downward trends as do four other countries. Japan is one 


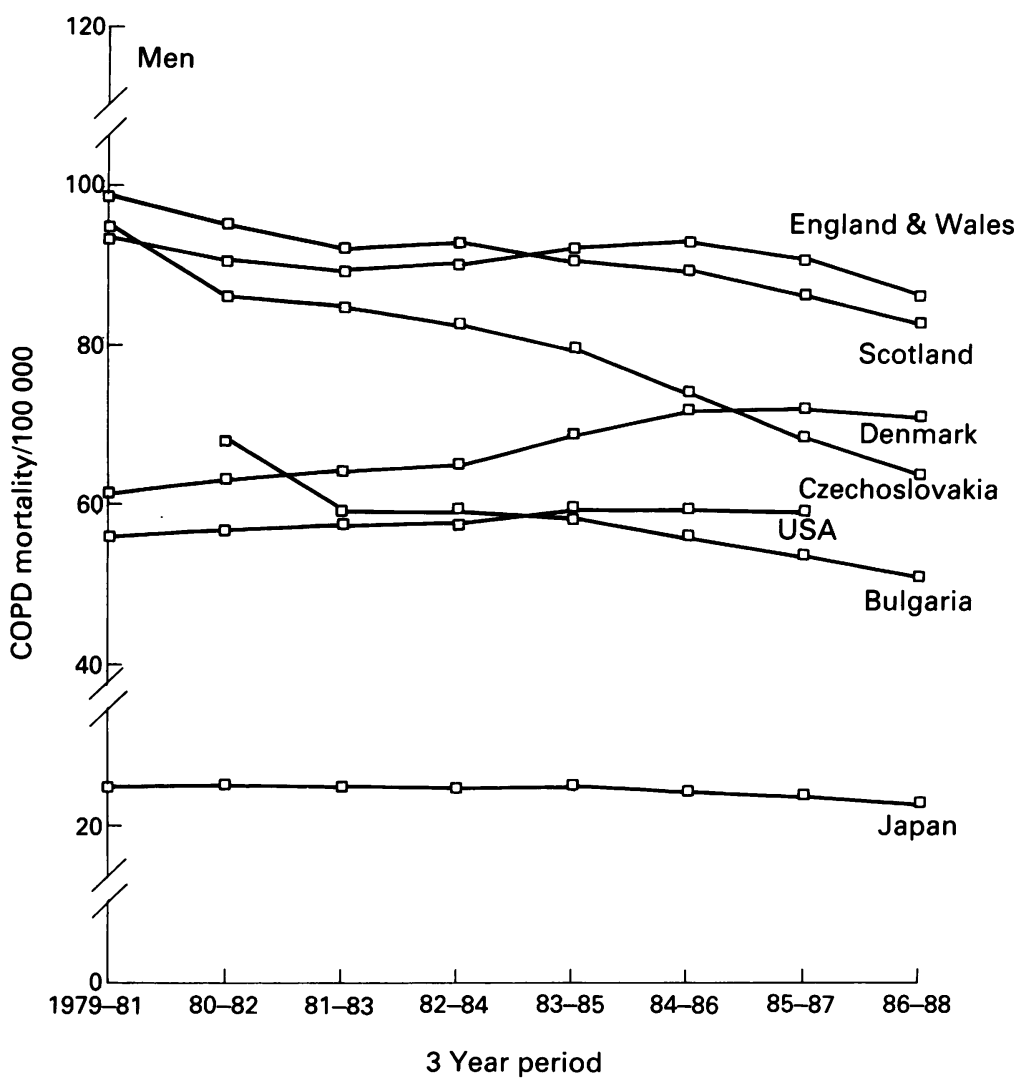

Figure 2 Trends in chronic obstructive pulmonary disease mortality in men aged 35-74 years. (Three year averages for 1979-88.)

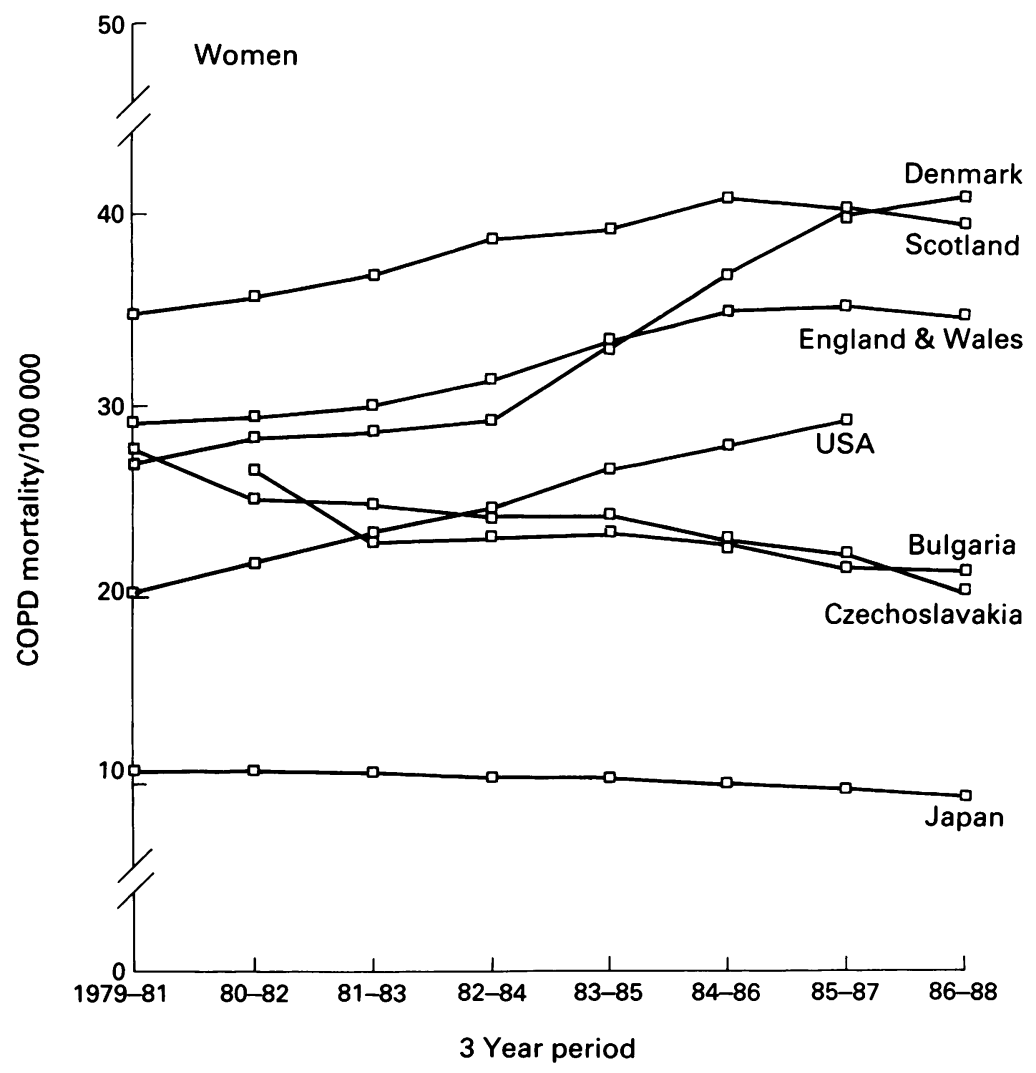

Figure 3 Trends in chronic obstructive pulmonary disease mortality in women aged 35-74 years. of nine countries whose rates remained constant over the period.

CORRELATIONS BETWEEN COPD MORTALITY AND CURRENT SMOKING LEVELS

To attempt to explain the widely differing COPD mortality in the 31 countries, data on the percentage of current smokers were obtained for both men and women for the most recent year available. Table 1 lists the percentages of current smokers for the 25 countries (UK countries combined) for which data were available. Rank correlations were calculated between the percentage of current smokers in each country and the COPD rate for the year that the smoking rate is given. For men, there was little relationship between COPD mortality and levels of current smoking with a correlation coefficient of -0.08 . Women showed a stronger relationship between COPD mortality and current smoking, with a correlation coefficient of 0.27 but this is not significant at the $5 \%$ level.

The relationship between the COPD male:female ratio and the percentage of current smokers (male:female ratio) was examined, and a correlation coefficient of 0.32 was obtained. When Japan, whose very high rate of cigarette smoking in men was incongruous with the very low rate of COPD, was omitted the correlation coefficient was 0.37 , which is significant at the $5 \%$ level.

CORRELATIONS BETWEEN COPD MORTALITY AND PAST LEVELS OF CIGARETTE CONSUMPTION

A limitation of the analysis using the percentage of current smokers is that it may be past cigarette consumption that influences current mortality. Unfortunately, data on current smokers over time are incomplete or absent for many countries. An extensive search found

Table 1 The percentages of current smokers (year in brackets) for both men and women

\begin{tabular}{lll}
\hline Country (y) & \multicolumn{2}{l}{$\%$ Current smokers } \\
\cline { 2 - 3 } & Men & Women \\
\hline Australia (1986) & $33 \cdot 0$ & $28 \cdot 0$ \\
Austria (1981) & $33 \cdot 0$ & $22 \cdot 0$ \\
Belgium (1984) & $35 \cdot 0$ & $21 \cdot 0$ \\
Bulgaria* & - & - \\
Canada (1987) & $36 \cdot 0$ & $32 \cdot 0$ \\
Czechoslovakia (1984) & $57 \cdot 0$ & $14 \cdot 0$ \\
Denmark (1987) & $49 \cdot 0$ & $38 \cdot 0$ \\
East Germany* & - & - \\
Republic of Ireland (1982) & $39 \cdot 0$ & $32 \cdot 0$ \\
Finland (1985) & $35 \cdot 0$ & $17 \cdot 0$ \\
France (1983) & $50 \cdot 0$ & $29 \cdot 0$ \\
Greece (1985) & $54 \cdot 0$ & $13 \cdot 0$ \\
Iceland* & - & - \\
Israel (1987) & $38 \cdot 0$ & $25 \cdot 0$ \\
Italy (1983) & $46 \cdot 0$ & $18 \cdot 0$ \\
Japan (1984) & $66 \cdot 0$ & $14 \cdot 0$ \\
Netherlands (1983) & $44 \cdot 0$ & $35 \cdot 0$ \\
New Zealand (1981) & $35 \cdot 0$ & $29 \cdot 0$ \\
Norway (1986) & $39 \cdot 0$ & $31 \cdot 0$ \\
Poland (1985) & $60 \cdot 0$ & $34 \cdot 0$ \\
Portugal (1984) & $37 \cdot 0$ & $10 \cdot 0$ \\
Romania (1980) & $48 \cdot 0$ & $13 \cdot 0$ \\
Spain (1982) & $58 \cdot 0$ & $20 \cdot 0$ \\
Sweden (1986) & $26 \cdot 0$ & $28 \cdot 0$ \\
Switzerland (1981) & $46 \cdot 0$ & $29 \cdot 0$ \\
United Kingdom (1988) & $33 \cdot 0$ & $30 \cdot 0$ \\
USA (1987) & $31 \cdot 5$ & $27 \cdot 0$ \\
West Germany (1984) & $44 \cdot 0$ & $29 \cdot 0$ \\
Yugoslavia* & - & - \\
\hline A Data not availate. & & \\
\hline
\end{tabular}

* Data not available. 
data on past levels of current smokers for four countries only. The trends in past levels of smoking for these countries were compared with COPD trends for both sexes, but contradictory patterns were seen.

Data on the percentage of ever smokers for both men and women were also obtained for 10 countries. Correlation coefficients of -0.09 for men and 0.22 for women were obtained when performing rank correlations between the COPD rate and the percentage of ever smokers. Neither of these were significant.

Only data on the total number of cigarettes consumed could be obtained to examine past levels of smoking for most of the countries. Cigarette consumption data are not available for men and women separately. In subsequent analyses examining relationships between consumption levels and rates of COPD, men and women have been analysed both separately and using a combined rate (the simple mean of the male and female rates).

Rank correlations between the percentage of current smokers and cigarette consumption for the same year (or nearest year) were performed for 24 countries for which data were available (Bulgaria, East Germany, Iceland, New Zealand, and Yugoslavia excepted). Correlation coefficients of $0.26,-0.01$, and 0.19 were obtained for men, women, and men and women combined respectively, and none were significant at the $5 \%$ level.

The relationship between past levels of cigarette consumption and COPD mortality over the period 1982-84 was examined using the consumption data (Fig 4). Starting at 1980 and going backwards, significant (at the 5\% level) correlations for men were obtained only in 1965 and 1955. Examination of individual calendar years showed clusterings of significant correlation coefficients in the late 1940s, mid 50s, and mid 60s. A similar analysis using female mortality (Fig 4) produced correlation coefficients smaller than those of men, with the only significant coefficient being in $1945(0.39$, $\mathrm{p}<0.05)$. Using COPD rates for other three

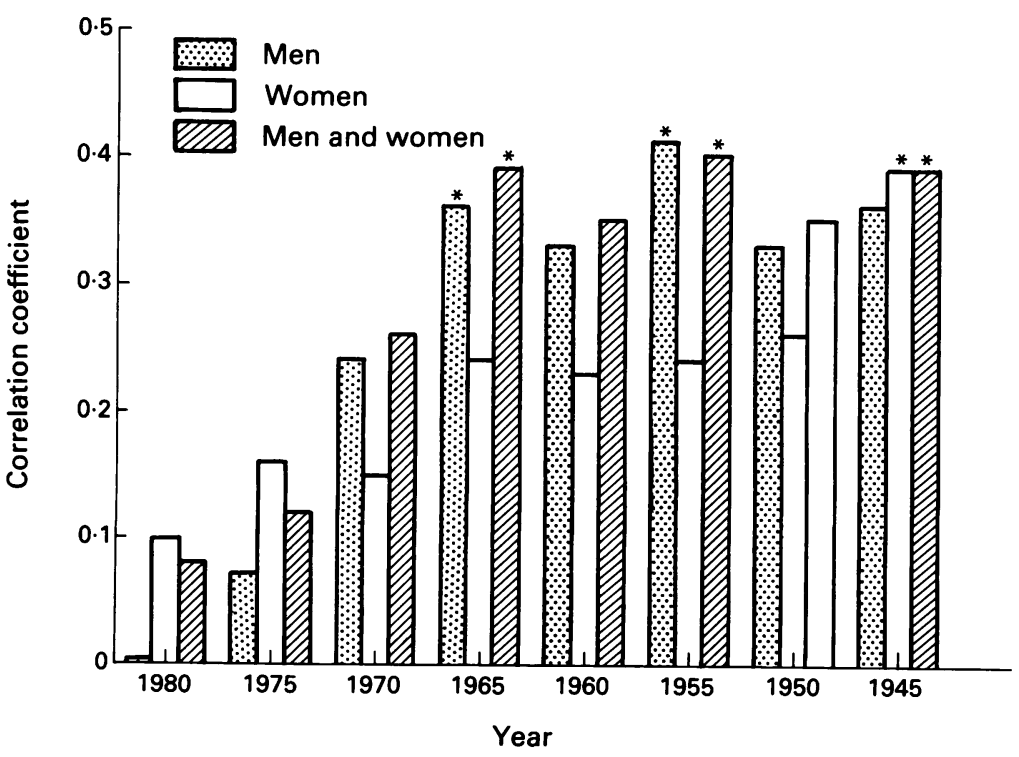

Figure 4 Correlations between past levels of cigarette consumption and chronic obstructive pulmonary disease rates (1982 to 1984) for men and women. year periods between 1979 and 1988 gave a similar pattern to that of the 1982-84 period.

COMPARISON OF TRENDS IN COPD MORTALITY WITH TRENDS IN CIGARETTE CONSUMPTION The lack of relationship after 1965 between levels of cigarette consumption and COPD mortality could reflect systematic differences between countries in their reporting of consumption. This should not affect the comparison of trends over time, and cigarette consumption trends were thus compared with COPD trends to see if a relationship over time could be established. Table 2 shows the absolute change in cigarette consumption per adult between 1975 and 1985 and between 1965 and 1975 , and the absolute change in COPD mortality from 1979-81 and 1986-88. The countries are grouped into the three categories of COPD trends used in Figure 2 for men. Of the 15 countries with a decrease in COPD mortality in men, only six countries showed a decline in consumption from 1975-85. For the period 1965-75, only Finland showed a decline in consumption (albeit small). Three of the nine countries with an increase in male COPD mortality (Spain, Austria, and France) had an increase in cigarette consumption from 197585 , while only the USA (Israel not known) showed no increase over the period 1965-75. Many inconsistencies are also seen for women. Combining male and female COPD rates, the pattern is similar to that of men alone. Comparison of COPD trends with cigarette consumption trends for other time periods (1970$80,1960-70,1970-85,1965-85$ ) showed a similar large number of inconsistencies for both men and women.

\section{Discussion}

This paper shows a wide diversity in rankings and trends of COPD from 1979-88 for both men and women. English speaking countries along with Romania and East Germany still have the highest COPD mortality and Japan and Greece still have the lowest rates. Most countries show either a decrease or no change in mortality in men, but in women, most show an increase. Using different measures of cigarette smoking could not explain the differing worldwide COPD mortality.

The wide variation in COPD mortality cannot easily be explained. In England and Wales, ${ }^{7}$ it was found that doctors were more likely to code a death as chronic airways disease, where previously they would have coded it as chronic bronchitis. In the USA, ${ }^{21}$ chronic bronchitis accounts for only approximately $5 \%$ of all COPD (ICD/9 490-496) deaths: in contrast, chronic airways disease accounts for almost $70 \%$ of all COPD deaths. With two countries still not having adopted the ICD ninth revision, three Scandinavian countries having only recently adopted it, and many eastern European countries still coding most COPD deaths as 490 to $493,{ }^{2}$ it is likely that this will affect comparison of international COPD mortality. 
Table 2 Absolute changes in cigarette consumption and chronic obstructive pulmonary disease (COPD) mortality

\begin{tabular}{|c|c|c|c|c|c|}
\hline \multirow[t]{2}{*}{ Country } & \multicolumn{2}{|c|}{$\begin{array}{l}\text { Absolute change in cigarette } \\
\text { consumption for two time periods }\end{array}$} & \multicolumn{3}{|c|}{$\begin{array}{l}\text { Absolute change in COPD mortality } \\
\text { between } 1979-81 \text { and } 1986-88\end{array}$} \\
\hline & $\begin{array}{l}\text { Period } \\
1975-85\end{array}$ & $\begin{array}{l}\text { Period } \\
1965-75\end{array}$ & Men & Women & Both \\
\hline $\begin{array}{l}\text { Czechoslovakia } \\
\text { Bulgaria } \\
\text { East Germany } \\
\text { Greece } \\
\text { Portugal } \\
\text { New Zealand } \\
\text { Finland } \\
\text { Yugoslavia } \\
\text { United Kingdom } \\
\text { Australia } \\
\text { West Germany } \\
\text { Italy } \\
\text { Switzerland } \\
\text { Romania } \\
\text { Sweden }\end{array}$ & $\begin{array}{l}+470 \\
+140 \\
+300 \\
+510 \\
-70 \\
- \\
-160 \\
+480 \\
-1090 \\
- \\
-250 \\
+340 \\
-90 \\
+210 \\
-200\end{array}$ & $\begin{array}{l}- \\
- \\
- \\
+1200 \\
+670 \\
\quad+230^{*} \\
-40 \\
- \\
+530 \\
+400^{*} \\
+560 \\
+580 \\
\quad 0 \\
-\quad 0\end{array}$ & $\begin{array}{l}-30 \cdot 8 \\
-16.7 \\
-16 \cdot 1 \\
-14 \cdot 3 \\
-12.3 \\
-11 \cdot 0 \\
-10 \cdot 1 \\
-9.2 \\
-7.6 \\
-6.9 \\
-5 \cdot 8 \\
-4 \cdot 8 \\
-3.5 \\
-2.9 \\
-2.4\end{array}$ & $\begin{array}{l}-7 \cdot 3 \\
-5.3 \\
-1.6 \\
-9.3 \\
-4.9 \\
+5.8 \\
+0.8 \\
-3.4 \\
+5.3 \\
+6.7 \\
-0.8 \\
-1.2 \\
+0.7 \\
-5.0 \\
-1.5\end{array}$ & $\begin{array}{r}-19.1 \\
-11.0 \\
-8.9 \\
-11.8 \\
-8.6 \\
-2.6 \\
-4.7 \\
-6.3 \\
-1.2 \\
+0.1 \\
-3 \cdot 3 \\
-3.0 \\
-1.4 \\
-4.0 \\
-2 \cdot 0\end{array}$ \\
\hline $\begin{array}{l}\text { Netherlands } \\
\text { Spain } \\
\text { Denmark } \\
\text { Belgium } \\
\text { Israel } \\
\text { Austria } \\
\text { USA } \\
\text { France } \\
\text { Canada }\end{array}$ & $\begin{array}{l}-1370 \\
+630 \\
-100 \\
-390 \\
- \\
+230 \\
-680 \\
+230 \\
-\end{array}$ & $\begin{array}{c}+1040 \\
+350 \\
+710 \\
+350 \\
- \\
+420 \\
-90 \\
+660 \\
+140^{*}\end{array}$ & $\begin{array}{r}+10.5 \\
+10.0 \\
+9.8 \\
+5.9 \\
+5.5 \\
+4.0 \\
+3.3 \\
+2.8 \\
+2.0\end{array}$ & $\begin{array}{r}+5.5 \\
+1.3 \\
+13.0 \\
+2.2 \\
+6.2 \\
+2.2 \\
+9.0 \\
+2.7 \\
+4.5\end{array}$ & $\begin{array}{r}+8 \cdot 0 \\
+5 \cdot 7 \\
+10.9 \\
+4.1 \\
+5.9 \\
+3.1 \\
+6 \cdot 2 \\
+2.8 \\
+3.3\end{array}$ \\
\hline $\begin{array}{l}\text { Japan } \\
\text { Poland } \\
\text { Eire } \\
\text { Norway } \\
\text { Iceland }\end{array}$ & $\begin{array}{r}-150 \\
+70 \\
-930 \\
-50 \\
+80\end{array}$ & $\begin{array}{c}+1070 \\
- \\
+800 \\
+220 \\
+1080\end{array}$ & $\begin{array}{l}-1.9 \\
+1.9 \\
-1.5 \\
-1.1 \\
-0.7\end{array}$ & $\begin{array}{r}-1.4 \\
0.0 \\
+3.2 \\
+3.5 \\
+4.9\end{array}$ & $\begin{array}{r}-1.7 \\
1.0 \\
+0.9 \\
+1.2 \\
+2.1\end{array}$ \\
\hline
\end{tabular}

* Time period 1965-73. remains static over the time period. If data on past levels of percentage smoking for both sexes were available for many more countries than the four in this paper, a relationship between past cigarette smoking and COPD trends might emerge.

This lack of a relationship between COPD mortality and measures of cigarette consumption could be caused by inadequate reporting of COPD or smoking, or both, in many countries. The 31 countries used in this study were selected because they satisfied death certification and data availability criteria for a previous study on COPD. ${ }^{2}$ Two different measures of smoking were used but neither related very well to the differing worldwide levels and trends of COPD.

There does seem to be a smoking effect (albeit small) on rates of COPD within countries which is not seen between countries. Although the type of cigarette smoked is similar in developed countries, ${ }^{26}$ different styles of tobacco smoking between countries may not be accounted for properly. Hand-rolled cigarettes make up a large proportion of total cigarettes smoked in Australia, Canada, New Zealand, and Norway, ${ }^{18}$ and smokers of unfiltered cigarettes have been shown to have a higher prevalence of chronic bronchitis than smokers of filter cigarettes. ${ }^{27}$ The tar content of cigarettes has been shown to be related to chronic bronchitis symptoms in some studies, ${ }^{2829}$ but not others, ${ }^{3031}$ and countries with a high COPD mortality may have higher proportions of high tar cigarette smokers. A dose-response relationship has been shown between the number of cigarettes smoked and chronic bronchitis $^{2228}$ and a measure of the proportion of heavy smokers could be related to COPD mortality. Although cigarette smoking is recognised as the main risk factor, air pollution has also been recognised as a risk factor for chronic bronchitis, ${ }^{32}$ but the effect of this may be declining. ${ }^{33}$ It has also been suggested that infant mortality and deprivation in infancy are related to chronic bronchitis in later life. ${ }^{34}$

Stronger correlations than those shown between COPD mortality and cigarette smoking have been seen between lung cancer mortality and cigarette consumption. ${ }^{35} 36$ This may suggest that lung cancer mortality death certification is of a higher diagnostic validity than COPD death certification. These correlations, however, were still not as good as we would have expected. Interestingly, it is the same countries in both our study and those investigating lung cancer that have lower than expected mortality, suggesting either inadequate measurement of cigarette smoking or some other exacerbative or protective factor, or both.

In conclusion, it seems that the prevalence of cigarette smoking alone cannot explain the worldwide variation in COPD mortality. Other factors which may be involved include the type of cigarette smoked, the proportion of heavy smokers, tar content of cigarettes smoked, atmospheric pollution, and childhood deprivation. If national data on these factors were available for the countries studied, they could possibly disguise the male trend, especially where the male consumption level 
might explain the international differences. Alternatively, it is possible that there are factors other than those identified in the classic cohort studies that have not been identified, although this cannot be concluded from this paper. Study of these could give insight into the pathophysiology of COPD. Because COPD mortality has fallen very little overall $(0 \cdot 9 / 100000)$ for the 31 countries examined over the period $1979-88$, the need to investigate this is pressing.

C Brown is grateful for funding from the Scottish Home and Health Department. The opinions expressed are those of the authors and not of the funding body.

1 Bouvier MH, Guidevaux M. Mortality from disorders of the respiratory system throughout the world between 1950 and 1972. World Health Stat $Q$ 1979;32:174-97.

2 Thom TJ. International comparisons in COPD mortality. Am Rev Respir Dis 1989;140:S27-34.

3 Burney PGJ, Holland WW. The epidemiology of respiratory disease in the UK. Medicine International 1982;1:B124-6

4 Cooreman J, Thom TJ, Higgins MW. Mortality from chronic obstructive pulmonary diseases and asthma in France, 1969-1983. Comparisons with the United States France, 1969-1983. Comparisons with

5 Ciba Guest Symposium. Terminology, definitions, and Ciba Guest Symposium. Terminology, definitions, and classification of chronic pulmonary em
related conditions. Thorax 1959;14:286-99.

6 Cullinan P. Respiratory disease in England and Wales. Report. Thorax 1988;43:949-54.

7 Backhouse A, Holland WW. Trends in mortality from chronic obstructive airways disease in the United Kingdom. Thorax 1989;44:529-32.

8 Kelson MC, Heller RF. The effect of death certification and coding practices on observed differences in respiratory disease mortality in eight EEC countries. Rev Epidemiol Sante Publique 1983;31:423-32.

9 Farebrother MJB, Kelson MC, Heller RF. Death certification of farmer's lung and chronic airways diseases in different countries of the EEC. Br $\mathcal{F}$ Dis Chest different count

10 The US Surgeon General. The health consequences of smoking: chronic obstructive lung disease. A report of the Surgeon General. US Department of Health and Human Services, 1984

11 Higgins MW. Epidemiology of COPD. State of the art. Chest 1984;85(Suppl 6):3-8S

12 Waterhouse J, Correa P, Muir C, Powell J. Cancer incidence in five continents. Vol 3. Lyon: IARC, 1976;3:456.

13 Masironi R, Rothwell K. Smoking trends and effects worldwide. World Health Stat $Q$ 1988;41:228-41.

14 Hill DJ. Australian patterns of tobacco smoking in 1986. Med $\dot{f}$ Aust 1988;149:6-10.

15 Van Reek J. Smoking behaviour in the Netherlands. A st

16 Office of Population Censuses and Surveys. General household survey. London: HMSO, 1988.

17 Todd G. Statistics of smoking in the member states of the European Community. Luxembourg: Office for Official Publications of the European Community, 1986.

18 Lee PN. Tobacco consumption in various countries. Research paper 6, 4th ed. London: Tobacco Research Council, 1975.

19 Kristein MM. 40 years of US cigarette smoking and heart disease and cancer mortality rates. F Chron Dis 1984; 37:317-23.

20 Kristein MM. Japanese lung cancer mortality rates, 194780 and per capita cigarette consumption in Japan (letter). Int 7 Epidemiol 1986;15:140-1.

21 Higgins MW. Chronic airways disease in the United States: trends and determinants. Chest 1989;96:328S-34S.

22 Fletcher C, Peto R, Tinker C, Speizer FE. The natural history of chronic bronchitis and emphysema. An eight-year study of early chronic obstructive lung disease in working study of early chronic obstructive lung disease in working

men in London. London: Oxford University Press, 1976.
23 Beck GJ, Doyle CA, Schachter EN. A longitudinal study of respiratory health in a rural community. Am Rev Respir Dis 1982;125:375-81.

24 Leeder SR, Colley JRT, Corkhill R, Holland WW. Change in respiratory symptom prevalence in adults who alte their smoking habits. Am $\mathcal{F}$ Epidemiol 1977;105:522-9.

25 Jacobson B. Beating the ladykillers. Women and smoking. London: Victor Gollancz Ltd, 1988:8.

26 Smoking - worldwide trends and their implications. In: World Health Statistics Annual 1986. Geneva: WHO; 1619.

27 Comstock GW, Brownlow WJ, Stone RW, Sartwell PE. Cigarette smoking and changes in respiratory findings. Arch Environ Health 1970;21:50-7.

28 Higenbottam T, Clark TJH, Shipley MJ, Rose G. Lung function and symptoms of cigarette smokers related to tar yield and number of cigarettes smoked. Lancet tar yield and

29 Paoletti P, Camilli AE, Holberg CJ, Lebowitz MD. Respiratory effects in relation to estimated tar exposure from current and cumulative cigarette consumption. Chest 1985;88:849-55.

30 Petitti DB, Friedman GD. Respiratory morbidity in smokers of low- and high-yield cigarettes. Prev Med 1985;14:217-25.

31 Brown CA, Crombie IK, Smith WCS, Tunstall-Pedoe H. Cigarette tar content and symptoms of chronic bronchitis: results of the Scottish Heart Health Study. $\mathcal{F}$ Epidemiol Community Health 1991;45:287-90.

32 Royal College of Physicians. Air pollution and health. London: Pitman Medical and Scientific Publishing, 1970.

33 Chinn S, Florey C du V, Baldwin IG, Gorgol $M$. The relation of mortality in England and Wales 1969-73 to measurements of air pollution. 7 Epidemiol Community Health 1981;35:174-9.

34 Barker DJP, Osmond C. Childhood respiratory infection and adult chronic bronchitis in England and Wales. $B M \mathcal{F}$ 1986;293:1271-5.

35 Doll R. Etiology of lung cancer. Adv Cancer Res 1955;3:150

36 Doll R, Peto R. The causes of cancer. Quantitative estimates of avoidable risks of cancer in the United States today. 7 Natl Cancer Inst 1981;66:1191-308. 